\title{
Unusual caudal spines in the surgeonfish Zebrasoma scopas
}

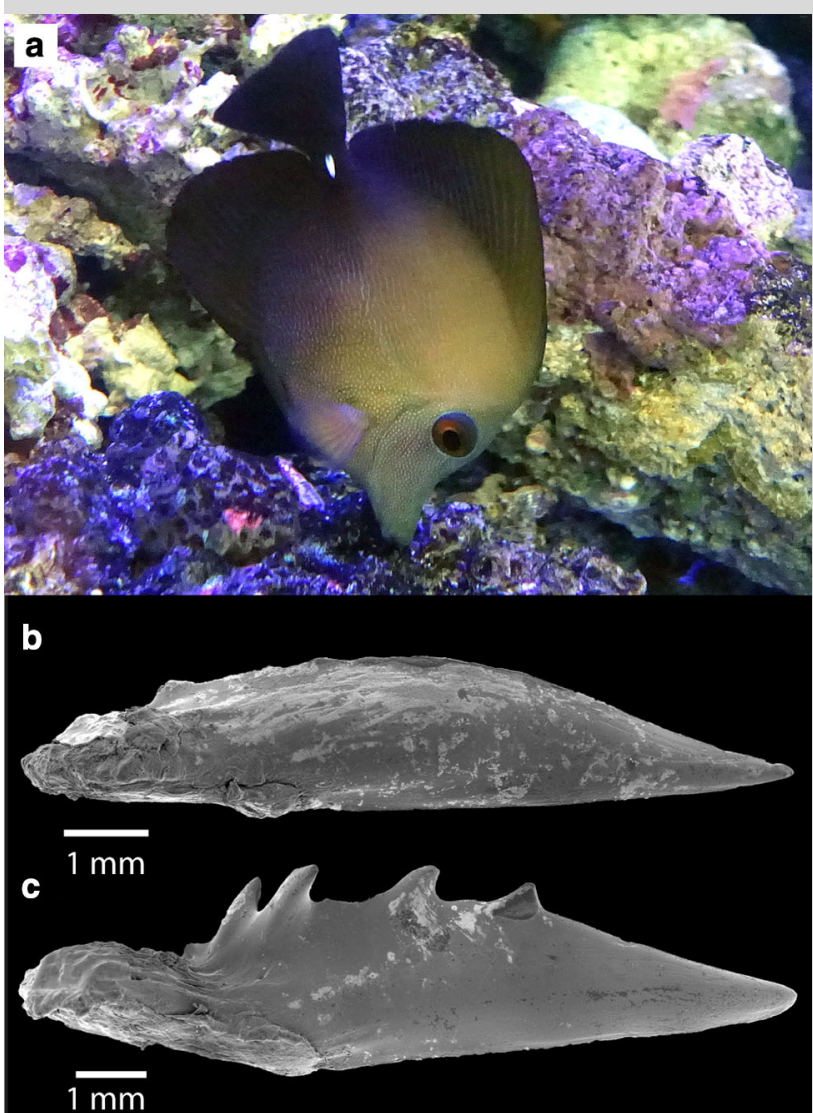

Fig. 1 a The surgeonfish Zebrasoma scopas. Scanning electron micrographs of b a regular smooth caudal spine and $\mathbf{c}$ an unusual caudal spine with forwardpointing spikes
Surgeonfishes (Acanthuridae) are found in tropical and subtropical marine ecosystems and typically comprise a core component of coral reef fish assemblages (Randall 1955). The surgeonfishes are disparate in terms of their morphology, feeding habits and behavioural tendencies, yet all share the distinct, unifying feature of at least one pair of scalpel-like modified scales on their caudal peduncle (Randall 1955) which can be used for defensive or territorial interactions (Schober and Ditrich 1992). Indeed, the common name 'surgeonfishes' is derived from the possession of these scalpellike caudal spines.

Marked intraspecific variability in caudal spine morphology was observed while performing morphological measurements on scopas tangs, Zebrasoma scopas (Fig. 1a). Most $Z$. scopas had smooth, sharp, retractable spines that came to a distinct point (Fig. 1b). However, some specimens had spines with distinct forward-pointing spikes, which became particularly apparent after examination using scanning electron microscopy (Fig. 1b, c). The unusual spines were found on both sides of an individual and appeared to be associated with a more pronounced patch of setae on the flanks of specimens. These remarkable forward-pointing spikes highlight the potential for intraspecific variability of morphological features.

Acknowledgements We thank S. Askew and V. Huertas for assistance with scanning electron microscopy and the Australian Research Council for financial support (DRB).

\section{References}

Randall JE (1955) A contribution to the biology of the Acanthuridae (surgeon fishes). Ph.D. thesis, University of Hawaii, Hawaii

Schober UM, Ditrich H (1992) Anatomy and use of the caudal spines in the aggressive behaviour of a surgeonfish (Osteichthyes: Acanthuridae). Mar Behav Physiol 21:277-284

S. B. Tebbett $(\bowtie) \cdot$ D. R. Bellwood

ARC Centre of Excellence for Coral Reef Studies and College of Science and Engineering, James Cook University, Townsville, QLD 4811, Australia e-mail: sterling.tebbett@my.jcu.edu.au 